\title{
Intraoperative recurrent laryngeal nerve monitoring during surgery for left lung cancer
}

\author{
Jinbo Zhao, MD, ${ }^{\text {a }}$ Hui Xu, MD, ${ }^{\mathrm{b}}$ Wenhai Li, MD, ${ }^{\mathrm{a}}$ Lianhong Chen, MD, ${ }^{\mathrm{a}}$ Daixing Zhong, MD, ${ }^{\mathrm{a}}$ and \\ Yongan Zhou, $\mathrm{MD}^{\mathrm{a}}$
}

Objective: This study evaluated the safety and efficacy of intraoperative recurrent laryngeal nerve monitoring during surgery for left lung cancer.

\begin{abstract}
Methods: From April 2008 to April 2009, a total of 25 patients at high risk for left recurrent laryngeal nerve injury agreed to and underwent intraoperative recurrent laryngeal nerve monitoring during surgery for left lung cancer in our hospital. Results and clinical records were reviewed.
\end{abstract}

\begin{abstract}
Results: All the patients' left recurrent laryngeal nerves were identified during operation by intraoperative recurrent laryngeal nerve monitoring. Twenty-four patients retained normal left recurrent laryngeal nerves after the operation. One patient, in whom part of the left recurrent laryngeal nerve was found to be invaded, underwent single-stage nerve anastomosis under recurrent laryngeal nerve monitoring after the invaded nerve was resected. There were no significant intraoperative or postoperative complications among the other patients.
\end{abstract}

Conclusions: Intraoperative recurrent laryngeal nerve monitoring during thoracotomy is a safe and effective way of identifying the nerve. It may help surgeons to avoid injuring the recurrent laryngeal nerve during some thoracic procedures. (J Thorac Cardiovasc Surg 2010;140:578-82)

\section{Earn CME credits at}

http://cme.ctsnetjournals.org

Recurrent laryngeal nerve (RLN) paralysis (RLNP) is a complication of thoracic surgery. Because of the specific anatomic location of the RLN, the incidence of RLNP, especially left RLNP, is higher for certain thoracic operations, such as surgery for left lung cancer, esophagectomy with 3-field lymph node dissection for carcinoma, and mediastinoscopy. ${ }^{1-3}$ Injury of the RLN can result in some symptoms, such as hoarseness, liquid aspiration, swallowing disorder, and ineffective cough, that adversely affect patients' quality of life and recovery after surgery.

To date, however, no effective means of avoiding injury to the RLN during thoracic surgery has been available. By recording compound electromyographic (EMG) action potentials from the RLN, any injury to the RLN could be identified during the operation, an application that has been widely used and studied in neck surgery, especially thyroid surgery. ${ }^{4,5}$ The studies from thyroid surgery have shown that

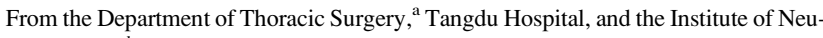
roscience, ${ }^{\text {b }}$ Fourth Military Medical University, Xi'an, Shaanxi, China. Disclosures: None.

J.Z. and H.X. contributed equally to this work.

Received for publication Sept 3, 2009; revisions received Jan 1, 2010; accepted for publication Jan 18, 2010; available ahead of print May 17, 2010.

Address for reprints: Yongan Zhou, MD, PhD, Department of Thoracic Surgery,

Tangdu Hospital, Fourth Medical Military University, Xinsi Rd, Xi'an, Shaanxi

710038, China (E-mail: zhou.yongan@163.com).

$0022-5223 / \$ 36.00$

Copyright (c) 2010 by The American Association for Thoracic Surgery doi:10.1016/j.jtcvs.2010.01.045
}

the RLN is less likely to be injured permanently if it is clearly visualized during the surgical procedure by intraoperative RLN monitoring (RLNM). ${ }^{6,7}$ Little research, however, exists regarding the application of RLNM to thoracic operations. In this study, we performed RLNM during surgery for left lung cancer to evaluate its safety and efficacy during thoracic operations.

\section{MATERIALS AND METHODS \\ Patients}

This study obtained the informed consent of all patients and was approved by our institutional ethics committee. From April 2008 to April 2009, patients who needed operation for left primary or suspected lung cancer and were at high risk for RLNP were enrolled in this research. The entry and exclusion criteria are shown in Table 1.

All patients enrolled in this study accepted assessment, including complete history, physical examination, complete blood cell count, biochemical profile, chest roentgenogram, computed tomographic scans of the chest and brain, ultrasonographic scan of the upper abdomen, electrocardiography, arterial blood gas measurement, routine pulmonary function tests, and fiberoptic bronchoscopy. Single-photon emission computed tomographic scans were performed for patients with anemia, bone pain, or elevated alkaline phosphatase or calcium levels to rule out bone metastasis. All patients underwent preoperative and postoperative evaluations of the movement of vocal cords by means of fiberoptic bronchoscopy.

\section{Intubation and Anesthesia}

All patients were intubated for general anesthesia with the Medtronic Xomed Nerve Integrity Monitor EMG endotracheal tube (Medtronic ENT, Jacksonville, Fla), which has 2 exploratory electrodes above the cuff (Figure 1). To ensure that the EMG can be recorded, the exploratory electrode should be adhered to each vocal cord during intubation. The correct location of the surface electrode was tested before and after positioning of the patient's body on the operating table.

All procedures were performed with standard general anesthesia. Cisatracurium besylate (INN cisatracurium besilate, a short-acting muscle 


\section{Abbreviations and Acronyms \\ $\mathrm{EMG}=$ electromyography \\ RLN = recurrent laryngeal nerve \\ RLNM $=$ recurrent laryngeal nerve monitoring \\ RLNP = recurrent laryngeal nerve paralysis}

relaxant) was given to the patients for induction and maintenance of anesthesia. A neuromuscular monitoring (TOF-Watch SX; Organon Middle East Ltd, Cyprus) was used to monitor the effect of cisatracurium. Before the RLNM was performed, the first twitch percent was required to return to $50 \%$ to exclude the influence of muscle relaxants. ${ }^{9}$

\section{Modified 4-Step Intraoperative RLNM Procedure}

All patients underwent intraoperative RLNM with the NIM-Response system (Medtronic ENT) for EMG. The high-frequency electricity knife was not used during mapping of the left RLN. To standardize and evaluate the procedures, we modified the 4-step procedure of intraoperative RLMN that had been used during thyroid surgery as follows ${ }^{4}$ (Figure 1).

Step 1. For V1 signal detection, an original EMG signal was obtained from the vagus nerve before identification of the RLN. The nerve was tested by being directly touched with the nerve stimulator. The stimulation level was set at $0.5 \mathrm{~mA}$ as a starting point, and the event threshold at $100 \mu \mathrm{V}$; if no signal was elicited, the stimulation was increased gradually to 3.0 $\mathrm{mA}$. Equipment failure was considered if a $\mathrm{V} 1$ signal could not be received at a level of $3.0 \mathrm{~mA}$.

Step 2. For R1 signal detection and RLN mapping, the signal was obtained from the originating site of RLN along the vagus nerve. Then the course of the RLN was labeled. During the operation, the signal was detected before suspected trabeculae were dissected.

Step 3. For R2 signal detection, the signal was obtained by stimulating the RLN after the tumor and lymph nodes had been completely dissected.

Step 4. For V2 signal detection, the final testing of the vagus nerve was performed after complete hemostasis of the operative field.

\section{Intraoperative and Postoperative Assessments}

Before RLNM was used during the operation, the left RLN and its course were firstly judged by the surgeon. Three kinds of judgment (right, uncertain, or wrong), relative to the later identification of the left RLN by RLNM, were recorded. The RLNM was then used to identify the left RLN and its course. The 4 kinds of signals were recorded. If the V1 and R1 signals were recorded, it was considered that the left RLN and its course had been identified. If either the R2 or V2 signal was lost, it was determined that the left RLN was injured. After surgery, hoarseness, stridor, feeding difficulties, and voice changes were assessed 24 hours and 3 months after operation.

\section{RESULTS}

From April 2008 to April 2009, a total of 25 patients (7 women and 18 men, 42-68 years old) who met the entry and exclusion criteria consented to intraoperative RLNM during thoracotomy. Patients' clinical characteristics and details of the operations are summarized in Table 2.

With RLNM, all the V1 and R1 signals were detected, meaning that the left RLNs of all the patients were found and detected. During operations, all except patient 12 had R2 and V2 signals detected. Before the use of RLNM, the surgeon made 8 correct judgments, 10 uncertain judgments,
TABLE 1. Inclusion and exclusion criteria

\begin{tabular}{ll}
\hline \multicolumn{1}{c}{ Inclusion criteria } & Exclusion criteria \\
\hline T stage $\geq 2$ & Pacemaker \\
$\geq 1$ node $(\mathrm{L} 4,5,6)$ shortest axis $>1.0 \mathrm{~cm} *$ & Severe heart disease \\
& No informed consent \\
\hline By computed tomography. &
\end{tabular}

and 7 misjudgments. The mean time of mapping left RLN was $13.24 \pm 3.73$ minutes (range, 6-25 minutes). The mean evoked potential stimulated by current was $170.56 \pm$ $63.36 \mu \mathrm{V}$ (range, $101-348 \mu \mathrm{V}$ ). Interfering signals were caused by the stretch and the use of a high-frequency electric knife. The stretching was the primary cause of interfering signals. Although patient 12 had normal voice and vocal movement before the operation, it was found that the metastasis of lymph node station 5 had invaded the left RLN during operation. A portion of the left RLN was therefore resected. After removal of the tumor, we identified the ends of the left RLN with the help of RLNM and performed single-stage nerve anastomosis (Figure 2, A). RLNM showed that the $\mathrm{R} 2$ and $\mathrm{V} 2$ signals could be detected again after nerve anastomosis (Figure 2,B).

All patients except patient 12 retained normal voices after operation. There were no cases of hoarseness, stridor,

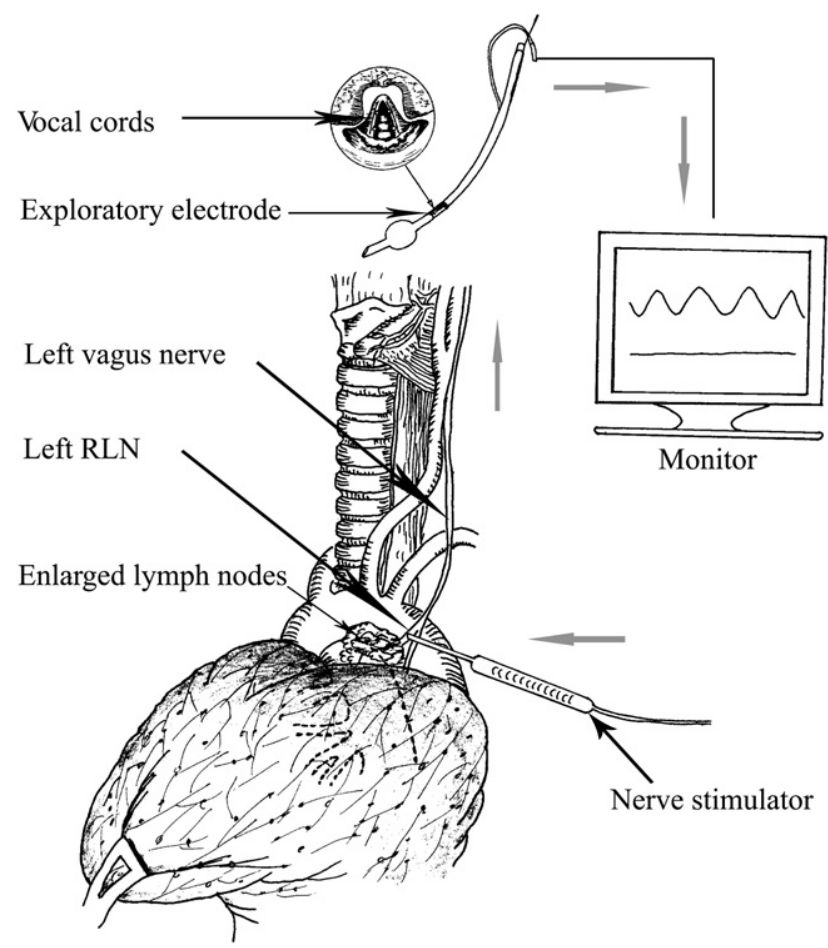

FIGURE 1. Procedure of intraoperative recurrent laryngeal nerve $(R L N)$ monitoring. Patient is intubated for general anesthesia with endotracheal tube with exploratory electrode above cuff. Nerve stimulator is used during operation, and electromyographic signals are recorded. If electromyographic signals cannot be recorded, recurrent laryngeal nerve is considered to be injured. 
TABLE 2. Characteristics of patients undergoing recurrent laryngeal nerve monitoring during left lung resection for cancer

\begin{tabular}{|c|c|c|c|c|c|c|c|c|}
\hline Case & Age (y) & Sex & Diagnosis & Operation & T status & Enlarged lymph nodes* & Postop complication & Postop RLNP \\
\hline 1 & 45 & M & SCC & $\mathrm{P}$ & $\mathrm{T}_{3}$ & $\mathrm{~L} 4,5$ & None & No \\
\hline 2 & 53 & $\mathrm{~F}$ & $\mathrm{AC}$ & LL & $\mathrm{T}_{2}$ & 5 & None & No \\
\hline 3 & 62 & M & SCC & SSR & $\mathrm{T}_{4}$ & $\mathrm{~L} 4,5$ & None & No \\
\hline 4 & 50 & M & $\mathrm{AC}$ & $\mathrm{UL}$ & $\mathrm{T}_{2}$ & 6 & None & No \\
\hline 5 & 65 & M & SCC & SSR & $\mathrm{T}_{3}$ & 5,6 & None & No \\
\hline 6 & 43 & M & SCC & $\mathrm{P}$ & $\mathrm{T}_{3}$ & $\mathrm{~L} 4,6$ & None & No \\
\hline 7 & 57 & $\mathrm{~F}$ & SCC & UL & $\mathrm{T}_{2}$ & $\mathrm{~L} 4,5$ & None & No \\
\hline 8 & 59 & M & SCC & UL & $\mathrm{T}_{2}$ & $\mathrm{~L} 4$ & None & No \\
\hline 9 & 60 & M & SCC & $\mathrm{P}$ & $\mathrm{T}_{3}$ & $\mathrm{~L} 4,5$ & None & No \\
\hline 10 & 62 & F & $\mathrm{AC}$ & SSR & $\mathrm{T}_{2}$ & $\mathrm{~L} 4$ & None & No \\
\hline 11 & 58 & F & SCC & UL & $\mathrm{T}_{2}$ & 5 & None & No \\
\hline 12 & 65 & M & SCC & $\mathrm{P}$ & $\mathrm{T}_{3}$ & 5,6 & $\begin{array}{l}\text { Hoarseness, } \\
\text { feeding difficulty }\end{array}$ & Yes \\
\hline 13 & 57 & $\mathrm{M}$ & $\mathrm{AC}$ & UL & $\mathrm{T}_{2}$ & 5,6 & None & No \\
\hline 14 & 64 & $\mathrm{M}$ & SCC & LL & $\mathrm{T}_{2}$ & 5 & None & No \\
\hline 15 & 66 & $\mathrm{M}$ & $\mathrm{AC}$ & $\mathrm{UL}$ & $\mathrm{T}_{2}$ & $\mathrm{~L} 4,6$ & None & No \\
\hline 16 & 53 & M & $\mathrm{AC}$ & $\mathrm{P}$ & $\mathrm{T}_{3}$ & $\mathrm{~L} 4,5$ & None & No \\
\hline 17 & 42 & $\mathrm{M}$ & SCC & UL & $\mathrm{T}_{2}$ & 5,6 & None & No \\
\hline 18 & 68 & $\mathrm{M}$ & SCC & LL & $\mathrm{T}_{2}$ & 5 & None & No \\
\hline 19 & 65 & M & SCC & UL & $\mathrm{T}_{2}$ & $\mathrm{~L} 4,5$ & None & No \\
\hline 20 & 53 & $\mathrm{M}$ & $\mathrm{AC}$ & $\mathrm{P}$ & $\mathrm{T}_{3}$ & $\mathrm{~L} 4,5$ & None & No \\
\hline 21 & 64 & $\mathrm{~F}$ & $\mathrm{AC}$ & SSR & $\mathrm{T}_{2}$ & $\mathrm{~L} 4,5$ & None & No \\
\hline 22 & 60 & $\mathrm{M}$ & SCC & $\mathrm{P}$ & $\mathrm{T}_{3}$ & $\mathrm{~L} 4,5$ & None & No \\
\hline 23 & 59 & $\mathrm{M}$ & SCC & LL & $\mathrm{T}_{2}$ & 5,6 & None & No \\
\hline 24 & 63 & F & $\mathrm{AC}$ & UL & $\mathrm{T}_{2}$ & $\mathrm{~L} 4$ & None & No \\
\hline 25 & 64 & $\mathrm{~F}$ & SCC & UL & $\mathrm{T}_{2}$ & $\mathrm{~L} 4,5$ & None & No \\
\hline
\end{tabular}

Postop, Postoperative; $R L N P$, recurrent laryngeal nerve paralysis; $M$, male; $S C C$, squamous cell carcinoma; $P$, pneumonectomy; $F$, female; $A C$, adenocarcinoma; $L L$, lower lobectomy; SSR, sleeve-shaped resection; $U L$, upper lobectomy. *All enlarged lymph nodes were positive.

feeding difficulties, or voice changes after extubation, after 24 hours, and 3 months after surgery. The current stimulation did not cause any complications, such as bronchospasm, arrhythmia, and postoperative gastrointestinal motility. Normal vocal cord movements were confirmed with fiberoptic bronchoscopy after the operation. Patient 12 had hoarseness after the operation, and the flexible bronchoscopy showed that the left vocal cord was fixed. Although we had performed the RLN anastomosis during surgery, the movement of left vocal cord hadn't recovered after 6 months.

\section{DISCUSSION}

In this study, we applied intraoperative RLNM during operation for left lung cancer and evaluated its safety and efficacy. Our results showed that intraoperative RLNM was effective to identify the left RLN, safe for patients, and helpful for surgeons to avoid injuring the nerve.
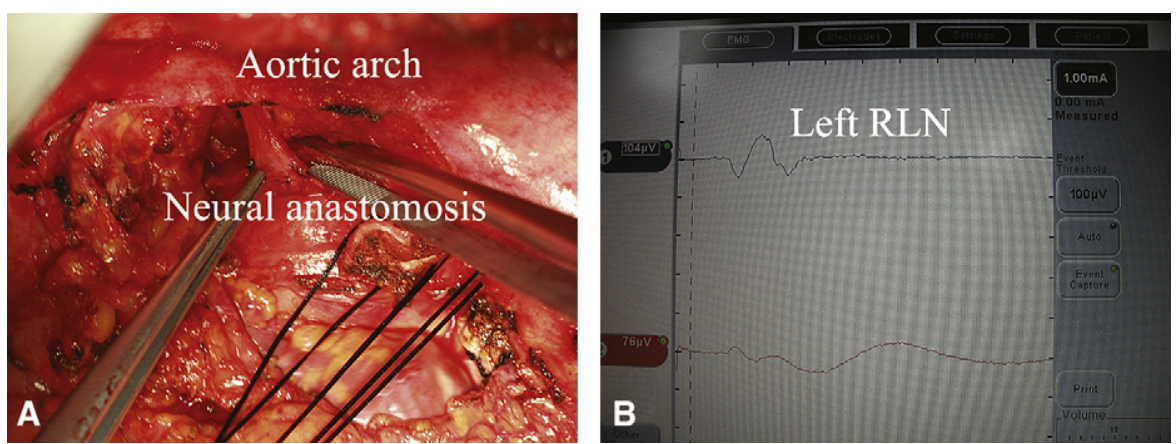

FIGURE 2. Single-stage recurrent laryngeal nerve $(R L N)$ anastomosis aided by intraoperative recurrent laryngeal nerve monitoring. Male 65-year-old patient underwent pneumonectomy and single-stage recurrent laryngeal nerve anastomosis for left squamous cell carcinoma. A, Part of invaded left recurrent laryngeal nerve was cut, and single-stage nerve anastomosis was performed with recurrent laryngeal nerve monitoring. B, Electromyogram obtained by vagal stimulation after nerve anastomosis by stimulating the vagus. 
The morbidity of RLNP is high during some thoracic operations. The incidence may be $31 \%$ among patients undergoing left lung resection for cancer, ${ }^{1}$ and even as high as $80 \%$ among those accepted for esophagectomy with 3-field lymph node dissection for carcinoma in Japan. ${ }^{10}$ There are 2 reasons for the high morbidity of RLNP, the anatomy and the interference of tumor. By dissecting human corpses, Liebermann-Meffert and colleagues ${ }^{11}$ showed that at the level of the aortic arch and above the left RLN may have multiple branches and is embedded in firm connective tissue, which increases the risk of RLN injury during pulmonary resection in this area. For patients with lung cancer, the nerve may be crushed by the enlarged lymph nodes or tumors around its course, which may make it more difficult to confirm the nerve. In Mom and associates' study, ${ }^{12} 11$ of 23 patients had left RLNP after left lung resections because of surgeons' indefinite judgment of the RLN or vagus nerve. Our study in a group of patients at high risk for RLNP showed that there were 10 uncertain judgments and 7 misjudgments among 25 judgments without RLNM, which implied that in total $68 \%$ left RLNs in this group could have been injured as the result of the surgeons' failure to identify the RLN. Finding an effective way to avoid the injury to the RLN is therefore essential for thoracic surgeons.

Intraoperative RLNM has been developed to detect EMG signals by stimulating the nerves with optimal current. Any injury to the nerve could be detected during operation if the EMG signals were lost after stimulation of the nerve with current. RLNM has been used successfully in neck surgery, especially thyroid surgery. ${ }^{4,6,7}$ Few studies, however, have addressed the application of RLNM during thoracic cardiac surgery. Odegard and coworkers $^{13}$ performed intraoperative EMG monitoring for patients with patent ductus arteriosus in whom the anatomic position of the left RLN was not affected. They found it effective and easy to identify the location and route of the RLN. Later, Hemmerling and associates ${ }^{9}$ first successfully performed intraoperative RLNM in the neck for a patient with esophageal carcinoma with suspected supraclavicular lymph node infiltration on the left side. Roberts and coworkers, ${ }^{14}$ however, showed that the role of RLNM was limited during mediastinoscopy because the traction in the anterior mediastinum caused the greatest stimulation to the nerves, even greater than direct stimulation with current. Until now, there have been no reports concerning the application of RLNM during thoracotomy in which the risk of left RLNP is high.

In our study, we showed that RLNM could efficiently help surgeons to identify the left RLN correctly during left thoracotomy. No complications, such as bronchospasm, arrhythmia, and postoperative gastrointestinal motility disorders, was caused by the current stimulation, and RLNM was safe. At the same time, RLNM yielded an opportunity to per- form single-stage nerve anastomosis to repair the damaged nerve during operation, which is a treatment for unilateral vocal fold paralysis. In our study, a part of the invaded left RLN was cut away successfully, and single-stage nerve anastomosis was performed for a patient with intraoperative RLMN. On intraoperative RLNM, the signal could be observed on stimulation of the vagus after the nerve anastomosis. This meant the continuity of the nerve had been rebuilt, yielding a chance for future recovery.

Stretching is the primary cause of RLN temporary or permanent injury in thyroid surgery, even with intraoperative neuromonitoring. ${ }^{4}$ Roberts and coworkers ${ }^{14}$ found the traction could interference the RLNM during mediastinoscopy. Benouaich and associates ${ }^{15}$ further showed that indirect stretch-induced injury may be a frequent mechanism for left RLNP. In our research, we found that stretching and the use of a high-frequency electric knife could produce interfering signals.

The ipsilateral RLN is easy to identify, but the contralateral RLN is difficult to monitor during thoracotomy. We have not yet found an effective method of monitoring bilateral RLNs during thoracotomy. In our study, discrete monitoring was used; however, real-time and continuous monitoring might be studied and used in future. The role of the intraoperative RLNM could be further confirmed with increased sample capacity in the future.

In conclusion, our study indicates that intraoperative RLNM during thoracic surgery could be a safe and effective means of identifying the RLN. As such, it could be useful in certain thoracic operations in which the RLN is at risk.

We thank colleagues from the department of anesthesiology for their cooperation on surgery and Ms Fang Zhao for preparing the illustrations.

\section{References}

1. Filaire M, Mom T, Laurent S, Harouna Y, Naamee A, Vallet L, et al. Vocal cord dysfunction after left lung resection for cancer. Eur J Cardiothorac Surg. 2001; 20:705-11.

2. Gockel I, Kneist W, Keilmann A, Junginger T. Recurrent laryngeal nerve paralysis (RLNP) following esophagectomy for carcinoma. Eur J Surg Oncol. 2005 31:277-81.

3. Witte B, Wolf M, Huertgen M, Toomes H. Video-assisted mediastinoscopic surgery: clinical feasibility and accuracy of mediastinal lymph node staging. Ann Thorac Surg. 2006;82:1821-7.

4. Chiang FY, Lu IC, Kuo WR, Lee KW, Chang NC, Wu CW. The mechanism of recurrent laryngeal nerve injury during thyroid surgery-the application of intraoperative neuromonitoring. Surgery. 2008;143:743-9.

5. Sobottka SB, Schackert G, May SA, Wiegleb M, Reiss G. Intraoperative facial nerve monitoring (IFNM) predicts facial nerve outcome after resection of vestibular schwannoma. Acta Neurochir (Wien). 1998;140:235-42.

6. Jatzko GR, Lisborg PH, Muller MG, Wette VM. Recurrent nerve palsy after thyroid operations-principal nerve identification and a literature review. Surgery. 1994;115:139-44.

7. Wagner HE, Seiler C. Recurrent laryngeal nerve palsy after thyroid gland surgery. Br J Surg. 1994;81:226-8.

8. Mountain CF, Dresler CM. Regional lymph node classification for lung cancer staging. Chest. 1997;111:1718-23. 
9. Hemmerling TM, Schmidt J, Jacobi KE, Klein P. Intraoperative monitoring of the recurrent laryngeal nerve during single-lung ventilation in esophagectomy. Anesth Analg. 2001;92:662-4.

10. Isono K, Sato H, Nakayama K. Results of a nationwide study on the three-field lymph node dissection of esophageal cancer. Oncology. 1991;48:411-20.

11. Liebermann-Meffert DM, Walbrun B, Hiebert CA, Siewert JR. Recurrent and superior laryngeal nerves: a new look with implications for the esophageal surgeon. Ann Thorac Surg. 1999;67:217-23.

12. Mom T, Filaire M, Advenier D, Guichard C, Naamee A, Escande G, et al. Concomitant type I thyroplasty and thoracic operations for lung cancer: prevent- ing respiratory complications associated with vagus or recurrent laryngeal nerve injury. J Thorac Cardiovasc Surg. 2001;121:642-8.

13. Odegard KC, Kirse DJ, del Nido PJ, Laussen PC, Casta A, Booke J, et al. Intraoperative recurrent laryngeal nerve monitoring during video-assisted thoracoscopic surgery for patent ductus arteriosus. J Cardiothorac Vasc Anesth. 2000;14:562-4.

14. Roberts JR, Wadsworth J. Recurrent laryngeal nerve monitoring during mediastinoscopy: predictors of injury. Ann Thorac Surg. 2007;83:388-91.

15. Benouaich V, Marcheix B, Carfagna L, Brouchet L, Guitard J. Anatomical bases of left recurrent nerve lesions during mediastinoscopy. Surg Radiol Anat. 2009; 31:295-9.

Access to The Journal of Thoracic and Cardiovascular Surgery Online is reserved for print subscribers!

Full-text access to The Journal of Thoracic and Cardiovascular Surgery Online is available for all print subscribers. To activate your individual online subscription, please visit The Journal of Thoracic and Cardiovascular Surgery Online, point your browser to http://www.mosby.com/jtcvs, follow the prompts to activate your online access, and follow the instructions. To activate your account, you will need your subscriber account number, which you can find on your mailing label (note: the number of digits in your subscriber account number varies from 6 to 10). See the example below in which the subscriber account number has been circled:

\section{Sample mailing label}

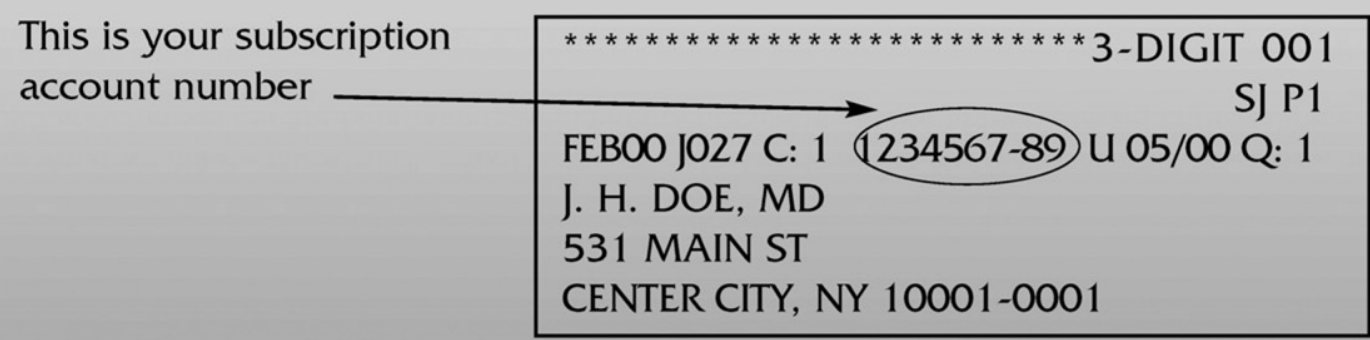

Personal subscriptions to The Journal of Thoracic and Cardiovascular Surgery Online are for individual use only and may not be transferred. Use of The Journal of Thoracic and Cardiovascular Surgery Online is subject to agreement to the terms and conditions as indicated online. 